\title{
Límites, reglas, comunicación en familia monoparental Con hijos adolescentes
}

\section{Boundaries, rules, interactional communication in single- parent family with family with teenage children}

\author{
Mildred Puello Scarpati ${ }^{*}$ \\ Corporación Universidad de la Costa, CUC, \\ Colombia \\ Marta Silva Pertuz \\ Universidad Metropolitana, Barranquilla, \\ Colombia \\ Adriana Silva Silva \\ Fundaciòn Universitaria Area Andina, Sede \\ Valledupar, Colombia.
}

Recibido: 2 de enero de 2014 Revisado: 3 de marzo de 2014 Aceptado: 1 de abril de 2014

\section{Resumen}

En este artículo se hace una revisión fundamentada en investigaciones a nivel local, nacional e internacional sobre los cambios que en la contemporaneidad han afectado la estructura familiar y han contribuido a nuevos tipos de familia. En este caso, el interés ha sido analizar las conclusiones de los investigadores sobre las familias monoparentales con hijos adolescentes encontrando diferencias en los resultados. Algunos investigadores señalan que este tipo de familia coloca en riesgo a los hijos adolescentes en temas de drogadicción, delincuencia; otros expresan que no se puede generalizar a todas las familias monoparentales, por esto es importante estudiar la función que desempeña el padre o la madre que lidera la familia, para favorecer el desarrollo psicológico de los hijos. Por lo anterior, se pretende estudiar en las familias monoparentales que se encuentran en la etapa vital de la adolescencia, su dinámica, especialmente los límites, reglas y comunicación interaccional como aspectos que organizan la convivencia en pro del desarrollo de sus integrantes, en especial de los adolescentes que están en la tarea vital de forjar su identidad.

Artículo de revisión. Proyecto Index: Análisis de los límites, Reglas y comunicación en familia monoparental con hijos adolescentes, Corporación Universidad de la Costa -CUC-.

Correspondencia: Mildred Puello Scarpati, Adriana Silva Silva, Marta Silva Pertus Correo electrónico: mpuello@cuc.edu.co. Dirección postal: Calle 58 No. 55-66, Facultad de Psicología, Corporación Universidad de la Costa -CUC-, Barranquilla, Colombia. 
Palabras clave: familia monoparental, comunicación interaccional, adolescencia, funcionamiento familiar, enfoque sistémico

\section{Abstract}

This article reviews local, national and international research on the changes that have affected the contemporary family structure and have contributed to new types of family. In this case, interest has centered in know the conclusions of the researchers on single-parent families with teenagers because they have found differences in the outcomes. Some researchers point out that this type of family place the children at risk for substance abuse, crime, etc., while others say that cannot be generalized to all single- parent families. So it is important to study the role of the father leading the family, the role exerted to promote the psychological development of children. Thus we wish to study in single-parent families that are in the life stage of adolescence, its dynamics, especially limits, rules and interactional communication as aspects that organize coexistence favoring the development of its members especially teenagers in the vital task of forging their identity.

Keywords: Interactional communication, single-parent family, teenager, family functioning, systemic approach

\section{Introducción}

Los estudiosos de la familia reconocen que es la célula más importante de la sociedad por la forma como influye en el desarrollo de las personas, y por su impacto en los procesos de educación y socialización. En la historia de la humanidad las dinámicas sociales, económicas, culturales y políticas, han cambiado el funcionamiento, roles, tareas e interacciones que han caracterizado a las familias de acuerdo a su contexto y época. Rodríguez (2004) explica la función educadora de la familia:

Colombia, país de regiones, cada una de ellas con particularidades sociales y culturales especiales, hacen imposible conocer la existencia de un tipo específico de familia colombiana. No obstante, Virginia Gutiérrez de Pineda, luego de décadas de brillantes investigaciones, concluyó que al margen de la sorprendente variedad de formas y arreglos familiares existentes en cada región, sobresale su presencia histórica. Extensa o reducida, fuerte $o$ fragmentada, próspera o pobre, patriarcal o, en ocasiones, matriarcal, autoritaria o afecti- va, la familia, siempre la familia, se nos presenta como la entidad social más distinguible en cada lugar de nuestra geografía. En la familia los colombianos han aprendido las maneras de ser regional, los gustos, el habla y el temperamento. En forma definitiva, la familia ha trazado el destino de cada individuo, pero también de nuestra estructura social; tanto en las pequeñas poblaciones como en las grandes ciudades. La familia en Colombia, conviene reconocerlo, no ha tenido una historia fácil, ni feliz. La formación de cada nuevo grupo familiar es una aventura. En su origen la sociedad colombiana, anudó en forma compleja tres grupos étnicos y culturales: los indígenas, los negros y los peninsulares. La conquista y la colonización constituyen el crisol donde se maceró el exterminio y el derrumbamiento de las sociedades indígenas, la importación y explotación de miles de africanos y el establecimiento de un grupo minoritario, pero triunfante, de españoles con fuertes principios culturales. El choque y cruce de estos grupos, con sus distintas costumbres, esparcieron en el territorio colombiano formas distintas de comprender y vivir la familia. (p. 247). 
Este marco referencial, identifica dos perspectivas: la primera, se enfoca en el papel educador de la familia, en los aspectos formativos, éticos, afectivos, sociales, económicos, culturales, ideológicos, intelectuales, morales de colombianos y, la segunda, denota la importancia de contextualizar a la hora de intervenirla, a la luz de esta multipluralidad geográfica, social, histórica.

Fundamentados en la comprensión histórica, se afirma que en la época feudal predominó la familia extensa patriarcal, integrada por varias descendencias. La industrialización y la urbanización contribuyeron a la aparición de la familia nuclear y estos cambios sociales generaron desafíos en la organización familiar. Por ello, para realizar una aproximación a este tema, es importante conocer las demandas de la familia en el contexto contemporáneo porque se parte de la premisa que los requerimientos de tiempos atrás no son los mismos retos asumidos por la familia tradicionalpatriarcal o nuclear.

Hoy, el incremento de madres solteras, padres solteros, viudos, divorcios, separaciones; la salida demorada de los hijos y el regreso de matrimonios al hogar paterno producto del desempleo o de rupturas matrimoniales, la violencia, la globalización, entre otros; están modificando la estructura familiar y originando nuevos tipos de familia, como la monoparental, tal como lo señalan Peck y Manocherian, (1988).

Otros cambios aparecen en su ideología y valores afectando el rol tradicional de la mujer, cuando esta busca trabajo fuera del hogar a partir de los años setenta. Este hecho la coloca en un nuevo lugar porque logra incorporarse en campos que anteriormente eran prohibidos. La casa deja de ser su centro de operación, su único rol no es el de ser cuidadora y protectora de los hijos, portadora de afectos, lo que imprime una nueva dinámica en la estructura de la familia nuclear y en los nuevos tipos de familia. Ahora se observa sustituyendo su papel en el hogar y ejerciéndolo papás, abuelas, nanas, hermanos mayores, vecinos, entre otros.

Los derechos humanos también han humanizado la relación padres e hijos, y esta ha evolucionado de posiciones verticales (autoridad-obediencia) ha relaciones horizontales. Los estudios de Uribe $(2007,2012)$ evidencian en el siglo XIX que las actitudes tiernas y el cuidado de los niños se consideraban como femeninos, y no era bien visto que los hombres los asumieran porque afectaba su masculinidad. Hoy, estos comportamientos son valorados socialmente y muestran un nuevo rol del padre en la crianza y educación de los hijos. Es así que se está cambiando el rol paterno y materno, el padre no es el centro de la autoridad ni de la economía en el hogar (rol proveedor/productivo). El factor demográfico se relaciona con la disminución de la fecundidad, el aumento de la esperanza de vida al nacer, la urbanización, el envejecimiento de la población. Desde lo cultural, surge un nuevo sentido de la feminidad, la mujer busca ser más autónoma, ser activa en la toma decisiones, distribución equitativa en el manejo del hogar en cuanto a labores domésticas, mayor independencia en el campo laboral y educativo. Estos datos se fundamentan en datos del Observatorio para la Equidad e Integración en Medellín y Antioquia, en su Informe de Coyuntura, (2006):

El creciente empoderamiento social y profesional de la mujer le ha dado mayor independencia frente a lo establecido por la familia patriarcal y le ha permitido tener confianza para asumir la maternidad como cabeza de familia, o decidir la terminación de la relación de pareja cuando considere que esta vulnera su desarrollo personal. El aumento de los divorcios y separaciones, y de mujeres que deciden ser madres sin tener pareja, ha significado también un aumento de los hogares con uno solo de los padres. Pero es especialmente preocupante el caso de mujeres cabeza de familia en estratos 1,2 y 3 que se ven obligadas a asumir la jefatura de hogar por la irresponsabilidad económica o falta de compromiso afectivo de su pareja. Como consecuencia se ha producido un cambio en los patrones de conformación de uniones conyugales y pareja, y se ha incrementado la inestabilidad en estas uniones (p. 4).

Colombia no escapa de las transformaciones que se están dando en las familias a nivel mundial, observándose en las últimas décadas un aumento de 
madres solteras, divorcios y una demora en el despegue de los hijos del hogar. Según Thomas (2013), la familia tradicional o nuclear está desapareciendo y se están generando nuevas composiciones familiares. No obstante, permanece el modelo de familia tradicional formada por un matrimonio con o sin generación que sigue considerándose como modelo de referencia para una gran parte de la población. Por otro lado, la familia nuclear empieza a abandonar su posición de patrón de referencia en la sociedad debido al incremento de rupturas matrimoniales que han generado nuevos tipos de familias. Esta se caracteriza por ser un grupo integrado por padres e hijos, con roles diferenciados en la pareja parental, clara división del trabajo, siendo el padre el proveedor económico y la madre se dedica a la crianza y educación de los hijos.

Estos cambios mencionados originan una nueva organización familiar: la monoparental, y es la razón para estudiar la dinámica de estas familias con hijos adolescentes, en cuanto a establecimiento de roles, del sentido de familia, de relaciones intra y extra-familiares. Por ello, en este artículo de revisión se analizarán conclusiones de investigadores que han relacionado este tipo de familia con embarazos a edades tempranas, delincuencia juvenil, como lo señala González, Carvajal y Salcedo (2011).

Al estudiar la familia monoparental se traza una ruta para comprender cómo su estructura lleva a cabo su función, establece límites y comunicación para el desarrollo psicológico de los hijos adolescentes. García y Constante (2011), expresan que la familia funciona de acuerdo con su tipología estructural, y cuando la familia es uniparental, las reglas, los roles, la jerarquía y la comunicación se ajustan para mantener el funcionamiento y adecuarse a la nueva estructura. Es decir, cuando se produce un cambio, se modifica todo el sistema familiar en sus funciones, roles, actividades e interacciones.

El presente artículo hace referencia a la investigación Límites, reglas, comunicación en familia monoparental con hijos adolescentes, pretende analizar la dinámica familiar: comunicación, establecimiento de límites, reglas en la etapa del ciclo vital con hijos adolescentes, la interrelación con el contexto para comprender como favorecen el cumplimiento de las nuevas tareas y roles, las relaciones de los padres y de padres-hijos, la construcción de la identidad del adolescente.

En este trabajo, cuando se habla de familia monoparental se refiere a las conformadas por un solo progenitor (hombre o mujer), los hijos dependen económicamente de uno de los padres, uno de ellos tiene a su cargo la custodia de hecho o por derecho, la jefatura puede ser masculina o femenina. Las familias monoparentales se originan por viudez, ruptura matrimonial, alejamiento forzado de uno de los padres (trabajo, inmigración, ingreso a prisión, secuestro, desaparición, desplazamiento forzoso, masacre producto del conflicto armado en el país) o por un nacimiento fuera del matrimonio.

Se toma como unidad de estudio la familia monoparental generada por una ruptura matrimonial, la ausencia de uno de los progenitores puede ser total, o parcial cuando el progenitor que no convive por decisión propia continúa desempeñando funciones relacionadas con la parentalidad, pero entre la pareja de padres no existe un vínculo afectivo de cohabitación como marido y mujer.

\section{La familia desde la perspectiva sistémica}

Según Bertalanffy (1992), todo organismo viviente es un sistema, es decir un conjunto dinámico de partes y procesos que interactúan recíprocamente entre sí y con el contexto donde se halla inmerso. Comprender para un observador la lectura sistémica de la familia, implica según Andolfi (1991), entender la relación entre el comportamiento individual y el grupo familiar enfocada en una observación que va más allá de ver las partes separadamente, de lo que dicen, focalizando interacciones, roles, formas de funcionamiento y de organización, conexiones como un todo o sistema.

En este orden de ideas, para Bouche (2003) la familia es un sistema dinámico, viviente sometido a un continuo establecimiento de reglas y de búsqueda de acuerdos a ellas. Esto coincide con Minuchin (1994), quien plantea que la familia es un 
grupo natural que en el curso del tiempo elabora pautas de interacción que constituyen: la estructura familiar, esta rige el funcionamiento de los miembros de la familia, define conductas y facilita su interacción recíproca. La familia necesita de una estructura viable para desempeñar tareas esenciales, apoyar la individualización al tiempo que proporciona un sentimiento de pertenencia.

Una investigadora de familia, propone con base en los desarrollos de la Teoría de Sistemas, la Cibernética y la Epistemología Cibernética, que "la familia es un sistema social natural que puede estudiarse en términos de su estructura, -la forma como está organizado en un momento dado- y sus procesos como cambios a través del tiempo" (Hernandez, 1997, 26).

La familia como sistema obedece al principio de no sumatividad, en cuanto a que el todo es mayor y diferente de la suma de sus partes, por lo cual no puede ser descrita simplemente por la adición de los rasgos de sus miembros individuales. La organización familiar y los patrones interaccionales implican un interjuego de la conducta de sus integrantes, de modo que lo que se enfoca en la observación del funcionamiento del sistema familiar son sobre todo los patrones de conexión y no solo el desempeño individual. La familia se ajusta como sistema al concepto de causalidad circular, en cuanto a que siendo un grupo de individuos interrelacionados, un cambio de ellos afecta a los demás y al grupo en total, en una cadena circular de influencia (Ibíd., p. 27).

Minuchin (1984), plantea que la familia se moviliza con base a estructuras como los límites, estos son espacios emocionales-físicos entre las personas, y la jerarquía corresponde a la autoridad en la familia, es quien determina la organización y las transacciones. Basado en esto, una familia es funcional o disfuncional por la capacidad de adaptación a variables como: exigencias sociales y evolutivas de sus integrantes; valores individuales y forma de enfrentar dilemas cotidianamente. Es así que se espera que el investigador de familia comprenda que los problemas familiares son el producto de dificultades en el ejercicio de la jerarquía familiar para establecer límites.
Un aspecto importante en la funcionalidad señalado por estudiosos en el tema, es que "una familia funcional no se define por la ausencia de estrés, conflicto o problemas, sino por cuán efectivamente los maneja para que no interfieran en el bienestar de sus miembros. Una familia disfuncional no puede cumplir con esta función" (Colapinto en Roizblatt, 2006, p. 219).

Desde lo sistémico las pautas interaccionales otorgan significado a las relaciones humanas y son particulares a la historia de cada familia, de su cultura y de sus creencias. Es decir, las interacciones evidencian relaciones y conexiones de los miembros de una familia y no se originan de manera lineal, de un individuo a otro sino de manera circular, lo que una hace afecta al otro, y lo que el otro hace afecta a esa persona, así que su conducta que es parte de esta interacción es el resultado de esta retroalimentación.

El individuo es la unidad más pequeña del sistema familiar, es un sujeto separado pero a la vez parte del conjunto familiar. El individuo, desde su personalidad y conducta, contribuye a las pautas familiares pero al mismo tiempo estas moldean la personalidad y sus formas de actuar. Desde un punto de vista sistémico, la conducta se explica como una responsabilidad compartida, surgida de pautas que provocan y mantienen las acciones del propio individuo (Colapinto y Minuchin, 2009, p. 32).

\section{Los límites en la estructura y convivencia familiar}

Minuchin (2003), expresa que la estructura familiar tiene la capacidad de ajustarse cuando hay cambios tanto internos y externos que contribuyen a que evolucione, a que asuma nuevos retos sin perder la identidad que proporciona seguridad y un marco de referencia a la familia. Sin embargo, cuando hay cambios, se resiste cuando se dan más allá de sus capacidades y hace por conservar pautas preferidas que ha mantenido durante cierto tiempo. Cuando se dan situaciones de desequilibrio como en el caso de las familias monoparentales, y se considera que algunos miembros 
no cumplen con sus responsabilidades aparecen exigencias de lealtad y estrategias para provocar sentimientos de culpabilidad.

La familia como sistema constituye su diferenciación y sus funciones por medio de subsistemas. Estos se constituyen por generación, sexo, interés o función. Cada persona de la familia pertenece a diferentes subsistemas en donde posee distintos niveles de poder y en los que aprende habilidades diferenciadas. En estos subsistemas se aprende a ser persona, a distinguirse cada integrante como "yo soy" y se desarrollan habilidades interpersonales.

Para Minuchin (2003), es muy importante para el funcionamiento de una familia el establecimiento de límites. Estos los constituyen las reglas, las cuales definen quiénes participan y de qué manera. La función de los límites es proteger la diferenciación de los integrantes del grupo familiar y el funcionamiento adecuado de la familia. Por ello, deben ser claros y han de definirse de la manera más precisa para permitir a las personas el desarrollo de funciones sin interrupciones y el contacto entre los miembros de un subsistema a otro.

Es decir, los límites demarcan el espacio entre una familia y otra, entre los miembros de un grupo familiar. Esta comprensión permite el ingreso al espacio donde se desenvuelve la familia, entender sus acciones y lo que acontece cotidianamente. Se puede leer como un mecanismo de protección de la familia ante los riesgos externos a que está expuesta.

Teniendo este referente, se comprenderá que las personas que conforman la familia monoparental ante los cambios, tratan de encontrar un equilibrio entre la forma como estaban acostumbrados a funcionar, a tener una organización y a las nuevas exigencias de su contexto. De igual manera, este marco de conocimientos es importante tenerlo presente en cualquier tipo de estructura familiar.

\section{Las reglas en la organización familiar}

Cusinato cita a Don Jackson (1992), manifestando que la familia funciona como sistema al definir reglas que contribuyan a que sus integrantes se comporten entre sí de manera organizada y repetitiva. Estos patrones de comportamiento los asume como principios que dirigen la vida familiar. En sus estudios de familia observaba que aquellas que funcionaban adecuadamente y se mantenían juntas era porque llegaban a un acuerdo de las relaciones que aceptaban, establecían límites y aceptaban diferencias que se daban en las relaciones. Sin embargo, las familias no definen las reglas solo de manera consciente aunque estuviesen de acuerdo en su relación con muchas de ellas.

Este autor propone que las reglas son un punto de trabajo de las familias porque muchas de ellas se establecen de manera no consciente, implícita y sus miembros no se dan cuenta, como consecuencia aparecen conflictos. Es así que las reglas en la familia se pueden inferir a partir de patrones redundantes de comportamiento que se observan en la interacción de los miembros.

La importancia de conocer las reglas de una familia es que permiten a las personas relacionarse, ser comprendidas y anticipar su comportamiento. Por esto, cuando un miembro se desvía de las reglas aparecen mensajes, gestos, etc., que señalan que no se permite y se entra en una zona de alerta que genera estrés y conflictos. Según Olhaberry y Farkas (2012), los comportamientos señalados de las personas por medio de la interacción son una metacomunicación que traduce que se desea que se corrija el comportamiento que no se permite y volver a lo que está permitido.

\section{Sentido y significado de la comunicación interaccional en la familia}

Según Watzlawick, Beavin y Jackson (1985) citados por López (1999), la comunicación cobra importancia porque su sentido aparece dentro de un contexto y el estudio de las relaciones de las personas en ese contexto particular cumple una función simbólica (mensaje, información), que es percibida y donde tiene sentido y significado. Por esto, la comunicación se basa en convenciones sociales y la realidad es un producto de la comunicación. Esta es muy importante para la familia, por ser un pro- 
ceso de interacción donde se construyen relaciones horizontales y verticales, se intercambian mensajes, informaciones, afectos, comportamientos.

Este autor plantea que, en la familia todo comportamiento es comunicación y como todo comportamiento tiene un valor comunicativo influye sobre los demás y es influido por los otros, por eso se dice que la comunicación es circular, porque tiene un mecanismo de retroalimentación. Fundamentados en este marco, la comunicación en la familia permite conocer pautas de interacción que emergen dentro de un contexto particular, no puede aislarse y tratarla como una dificultad individual o por la estructura de personalidad de esa persona. De esta manera el comportamiento sintomático de una persona adquiere sentido y función si se estudia en el contexto de las interacciones del grupo familiar.

\section{Aproximación conceptual a la familia monoparental}

Este estudio considera a la familia como un pilar importante en la sociedad, porque cumple funciones relacionadas con el cuidado, la protección y el desarrollo de sus miembros. El interés de estudiar la familia monoparental con hijos adolescentes se fundamenta en una lectura sistémica de la familia, que se asume en un todo integrado, diferente a la suma individual de sus miembros, que funciona con propiedades y características que emergen de las relaciones entre los miembros que la conforman, que hacen que su dinámica cuente con procesos, dispositivos que son diferentes a los que se dan en otro grupo familiar, que cambia durante en el paso de unas etapas vitales particulares y responde a las demandas de adaptación requeridas por el ambiente donde está inmersa. $Y$ en este marco de referencia se acepta el concepto planteado por Hernández (2005) sobre la familia.

Una definición completa de familia incluye por lo tanto tres perspectivas: una estructural relativa a los aspectos de composición, jerarquía, límites, roles, subsistema; otra funcional, relacionado con los patrones y fenómenos de la interacción; y otra evolutiva, donde se considera a la familia como un sistema morfo genético (p. 29).

\section{Familia monoparental}

Jociles, Rivas y Moncó (2008), analizan la dificultad que se dio en las ciencias sociales para delimitar y definir conceptualmente el término familia monoparental, que apareció en 1970. Fue a partir del libro de Schlesinger (1969) acogido por los estudiosos sobre la familia donde se empiezan a sustituir los nombres que recibían los matrimonios que se separaban o divorciaban, se les denominaba de manera descalificadora "familias incompletas", "padre solo", "madre sola cabeza de familia", "familias rotas", "familias descompuestas", "familias desunidas"... Iglesias de Ussel (1998), expresa que se concebía que estas situaciones familiares eran resultado de carencia y de fracaso. Lefaucher (1988), denota un aspecto valioso en las críticas feministas que reclamaban diferenciar la estructura familiar de quien era el proveedor de la familia para que a los hogares a cargo de la mujer se les diera el status de familia. De igual manera, mientras se daba esta redefinición de familia monoparental, por la comunidad académica aparecían cambios en las relaciones conyugales y cae el matrimonio como institución social, generando aumento de separaciones, de divorcios y nuevos tipos de familia como la monoparental.

Cuando hoy se habla de familias monoparentales, se refiere a aquellas en las que hay un solo progenitor, ya sea por muerte o separación o porque los hijos nacieron fuera del matrimonio. Otro tipo de familia monoparental se origina cuando se da un divorcio, los padres viven en casas diferentes pero continúan compartiendo la responsabilidad y compromiso con los hijos, este tipo de familia se llama binuclear. El adolescente vive con uno de sus padres pero cuenta con el apoyo de ambos.

Las familias monoparentales experiencian conflictos que se unen a cambios vitales que pasan los hijos, como la adolescencia. Desde un análisis sistémico, la adolescencia no solo la vivencian los hijos sino todos los integrantes de la familia, tal como lo mencionan Montañés, Bartolomé y Montañés (2008). Por ello, pueden aparecer dificultades como aislamiento social y soledad del padre, celos de los hijos, tensiones ocasionadas por relaciones amorosas del padre o madre a cargo de los hijos, dificultad para asumir límites y cumplir reglas cuan- 
do el progenitor trabaja fuera de la casa. Según Rodrigáñez ( 2008), los hijos se perciben diferente a los demás adolescentes que cuentan con padres que viven juntos, son hijos de fines de semana en la relación con el progenitor que no convive, con los hermanos que no conoce y a veces están obligados a convivir aunque no sea de su agrado. Los padres si no han resuelto la separación de su pareja cuentan con menos oportunidades relacionadas con la toma de decisiones y retroalimentación en conjunto, en beneficio del desarrollo y educación de los hijos, su estilo parental es sobreprotector o permisivo para compensar la pérdida o relación distante. Ritvo y Glick (2003), mencionan que este tipo de familia pasa por momentos continuos de ajuste dependiendo de la elaboración de situaciones en torno al padre ausente, así como en la asunción de roles que demanda la nueva estructura y organización familiar en cuanto a ser papá y mamá al mismo tiempo.

En los estudios realizados por autores como Barker y Verani (2008) y Arroyo (2002), se resalta la importancia de la participación de ambos padres en la formación de los hijos, las ventaja que esto proporciona se resume en hijos más democráticos en sus relaciones de género, equilibrio en la distribución de roles y funciones; lo que permite mayor espacio de crecimiento individual, desarrollo de mejores habilidades sociales, cognitivas y socio-afectivas. Esta investigación arroja que, en una familia con madre y padre comprometidos en la crianza de los hijos, contribuyen a que tengan mayores oportunidades a imitar, a ampliar sus habilidades para funcionar y adaptarse al contexto social. Sin embargo, señala que esta ventaja no se da en familias monoparentales porque en la mayoría de los casos estudiados los padres se separan y no trabajan en conjunto en beneficio del desarrollo de los hijos. Esta responsabilidad la asume el progenitor con quien viven los hijos y el otro padre es ausente.

\section{El ciclo vital en las familias monoparentales con hijos adolescentes}

Minuchin (1984) citado por Sánchez-Gutiérrez (2000), reconoce varias etapas en el desarrollo de la familia: formación, familia con hijos pequeños, familia con hijos escolares y adolescentes, familia con hijos mayores. Estas etapas son importantes no solo para cada uno de sus integrantes sino para la familia, porque los coloca frente a tareas que implican nuevos roles, adquisición de competencias y habilidades, renovación y ajustes en sus interacciones y vínculos que requieren para su desarrollo y el funcionamiento de la familia.

Según, Carrasco (1998) citado por Roizblatt (2006), las transformaciones que una familia vivencia en cada etapa del ciclo vital hace que no solo una persona se enfrente a los dilemas propios de ese periodo del desarrollo, sino que los demás también pasen por este. El autor plantea que: "las oscilaciones emocionales y de la conducta que acompañan la ejercitación de nuevas competencias y la innovación de los vínculos interactúan con los cambios que viven los padres con sus propias tareas evolutivas" (p. 429). Es así que, en cada fase del ciclo vital se generan cambios en la estructura y funcionamiento familiar. Por ejemplo en la etapa de la familia con adolescentes cambia el rol de este, la participación en algunas actividades familiares puede reducirse y aparecer discusiones o críticas a creencias y tradiciones familiares. En síntesis, Sánchez y Gutiérrez (2000) afirman que en esta etapa es importante consensuar actividades, tiempos, roles y responsabilidades.

Como la familia monoparental es un sistema familiar por un lado vivencia cambios no solo relacionados con ajustes en su nueva tipo de estructura, de organización sino experiencia transiciones correspondientes al ciclo vital familiar. Cualquiera que sea la causa de la monoparentalidad origina una disrupción del ciclo vital dando lugar a cambios en las reglas, en los límites y en las relaciones, lo que evidencia la necesidad de reorganización del sistema familiar. El grado de afectación de la familia dependerá de la fase del ciclo vital en donde ocurre la monoparentalidad, así como de otros factores relacionados con el contexto social, económico y étnico de la familia. En la investigación se analizará cómo se comprende la monoparentalidad originada por separación/divorcio en la etapa del ciclo vital familias con hijos adolescentes. 
Las familias monoparentales con adolescentes vivencian cambios muy significativos, porque la adolescencia es una etapa que trae consigo cambios a nivel físico, cognitivos, psicológicos y sociales. Los hijos comienzan su propio proceso para abandonar el hogar, formar su identidad y separarse de sus padres. La tarea clave es que los adolescentes logren una nueva definición del papel como hijos y ajustes en el rol paterno, porque los hijos ya no son niños, los padres deben resignificar su autoridad porque en esta etapa ya no son la autoridad absoluta, sin embargo los hijos requieren apoyo, firmeza, seguridad de los padres.

La inestabilidad del adolescente relacionada con su ciclo vital se une a los cambios que vivencia en su estructura familiar debido al divorcio, a su deseo de contar con un hogar estable, la necesidad de límites claros entre sus padres y él en cuanto a sexualidad, horarios de llegada a la casa, responsabilidades en la realización de labores en el hogar, colegio, permisos, etc.

Los adolescentes pueden afrontar el problema de dos formas distintas: los que previamente tienen dificultades, el divorcio es una carga añadida, aumentando el riesgo de sufrir problemas emocionales; los que no los tienen, la separación y los cambios que se producen en la vida familiar son percibidos como una experiencia de madurez. Unos $y$ otros pueden verse envueltos en conflictos no deseados de lealtad o asumir posiciones de culpa. También pueden verse obligados a aceptar el rol de progenitor con sus hermanos. Aunque en muchas ocasiones los adolescentes quisieran estar solos, este deseo no puede cumplirse porque cada padre busca la compañía de sus hijos para llenar su soledad. Pero cuando esto ocurre y los hijos llenan ese hueco, tiene un efecto negativo porque los aísla de otros compañeros e iguales y les impide cambiar.

Según Hernández (2005), en la adolescencia ocurren una serie de eventos psicológicos muy significativos para la persona. Estos sucesos influyen en sus relaciones familiares y sociales, en la búsqueda de autonomía, en el estilo personal de relacionarse y en la construcción de la identidad. Por estas razones, esta fase vital es una oportunidad para revisar su estilo de vida, poner a prueba valores y definir su criterio propio. Se plantea que en las familias con hijos adolescentes se bajan los niveles de cohesión familiar, ya que los jóvenes demandan privacidad, dejan la familia para estar más con los amigos, colocan nuevas exigencias como el respeto en sus puntos de vista, así difieran de los de la familia; señalan la necesidad de contar con comunicaciones más claras que permitan llegar a consensos sobre ciertos aspectos de la vida familiar, en lugar de imponer de manera absoluta los padres la autoridad, lo que genera tensiones.

\section{Una revisión meta-analítica de las tendencias investigativas en familia monoparental}

El punto de partida es hacer una exploración de estudios que se han generado sobre esta temática para contar con una visión más amplia de las discusiones y conclusiones de investigadores a nivel internacional. 
Tabla 1.

Síntesis meta-analítica de los estudios sobre familia monoparental a nivel internacional.

\begin{tabular}{|c|c|c|}
\hline Autores (Año) & $\begin{array}{c}\text { Título del } \\
\text { estudio }\end{array}$ & Síntesis analítica \\
\hline $\begin{array}{l}\text { Argentina } \\
\text { Cervini, Dari, } \\
\text { y Quiroz } \\
\text { (2014) }\end{array}$ & $\begin{array}{l}\text { Estructura } \\
\text { familiar y } \\
\text { rendimiento } \\
\text { académico } \\
\text { en países de } \\
\text { América Latina. } \\
\text { Los datos } \\
\text { del segundo } \\
\text { estudio regional } \\
\text { comparativo y } \\
\text { explicativo }\end{array}$ & $\begin{array}{l}\text { Este trabajo indaga el efecto de la configuración familiar sobre el rendi- } \\
\text { miento del estudiante en diversos tipos de estructura familiar y número de } \\
\text { integrantes, distinguiendo entre cantidad de hermanos y personas de } 18 \text { o } \\
\text { más años. Los estudiantes de familias completas obtienen puntajes más altos } \\
\text { que los que viven en monoparentales y aún más distante respecto de aque- } \\
\text { llos que pertenecen a otras estructuras familiares, donde viven sin ninguno } \\
\text { de los dos padres. Esta diferencia es más pronunciada en matemática que } \\
\text { en lectura. Por otra parte, cuanto mayor sea la cantidad de menores de } 18 \\
\text { años en la familia (proxy de cantidad de hermanos), más bajo será el nivel de } \\
\text { desempeño del estudiante en ambas asignaturas. Igual resultado deberá es- } \\
\text { perarse a medida que aumenta el número de personas de } 18 \text { años o más en la } \\
\text { familia. Todas estas distancias y asociaciones se mantienen estadísticamente } \\
\text { significativas aun cuando se controle por los antecedentes académicos del } \\
\text { estudiante y por el nivel socioeconómico y cultural de su familia. Es decir, la } \\
\text { configuración familiar tiene efecto aditivo propio, más allá del ejercido por } \\
\text { los antecedentes académicos y por el origen social del estudiante. }\end{array}$ \\
\hline $\begin{array}{l}\text { Anqi, y Yan } \\
\text { (2014). }\end{array}$ & $\begin{array}{l}\text { Los cambios en } \\
\text { las familias de } \\
\text { China continental } \\
\text { durante la } \\
\text { transición social: } \\
\text { un análisis crítico }\end{array}$ & $\begin{array}{l}\text { Se estudian cambios en la estructura familiar, valores y relaciones que evi- } \\
\text { dencian un rápido desarrollo social y económico en los últimos } 30 \text { años. Los } \\
\text { cambios en la vivienda, la educación y el mercado de trabajo han traído } \\
\text { oportunidades, opciones y riqueza, y al mismo tiempo plantea retos y es- } \\
\text { trés a las familias chinas durante la transición social. La evidencia empírica } \\
\text { muestra que la mayoría de las familias chinas ya no están controlados por } \\
\text { "Zuzhang", el jefe de una gran familia. Hay más familias nucleares que cual- } \\
\text { quier otro tipo de familias. Las familias extensas no parecen disminuir, son } \\
\text { muy funcionales para abordar las necesidades de los miembros y juegan un } \\
\text { papel fundamental durante las etapas de la crianza de los hijos y la muerte } \\
\text { en el ciclo de la vida familiar. Los datos muestran que los cambios en la } \\
\text { familia están influenciado por miles de años de historia y cultura, así como } \\
\text { por las políticas y las reformas. Las familias chinas contemporáneas adoptan } \\
\text { diversas formas: familia extendida temporal, familiares encabezados por sus } \\
\text { abuelos nucleares, familia monoparental, hogar con una sola familia, familia } \\
\text { con dos cabezas de familia, estos nuevos tipos de familia no se han converti- } \\
\text { do en las principales organizaciones familiares. Tal diversidad sugiere que la } \\
\text { modernización de la familia en China comporta diferentes formas sociales, } \\
\text { económicas y culturales que surgen después de la era de Mao, y las interac- } \\
\text { ciones entre todas estas influencias no establecen transformaciones en la } \\
\text { familia en un proceso lineal y por etapas como predice la teoría occidental } \\
\text { de la modernización. }\end{array}$ \\
\hline
\end{tabular}


Tabla 1.

Síntesis meta-analítica de los estudios sobre familia monoparental a nivel internacional.

\begin{tabular}{|c|c|c|}
\hline Autores (Año) & $\begin{array}{c}\text { Título del } \\
\text { estudio }\end{array}$ & Síntesis analítica \\
\hline $\begin{array}{l}\text { México } \\
\text { Lavielle- } \\
\text { Sotomayor, } \\
\text { Jiménez- } \\
\text { Valdez, } \\
\text { Vázquez- } \\
\text { Rodríguez, } \\
\text { Aguirre- } \\
\text { García, } \\
\text { Castillo-Trejo, } \\
\text { y Vega- } \\
\text { Mendoza } \\
\text { (2013) }\end{array}$ & $\begin{array}{l}\text { Impacto de } \\
\text { la familia en } \\
\text { las conductas } \\
\text { sexuales de } \\
\text { riesgo de los } \\
\text { adolescentes }\end{array}$ & $\begin{array}{l}\text { Esta investigación estudia la relación de las conductas sexuales de riesgo } \\
\text { en los adolescentes (uso inconsistente del condón, inicio temprano de las } \\
\text { relaciones sexuales y múltiples parejas sexuales) y las características de sus } \\
\text { familias en cuanto a satisfacción, dinámica y estructura familiar. Los resul- } \\
\text { tados arrojan una alta frecuencia de conductas sexuales de riesgo entre los } \\
\text { adolescentes. Se observó que } 29.7 \% \text { de los adolescentes había iniciado su } \\
\text { vida sexual activa y en la mayoría fue a temprana edad entre los } 14 \text { y } 15 \\
\text { años. Asimismo, } 24.4 \% \text { de los adolescentes habían tenido más de tres parejas } \\
\text { sexuales y } 48.2 \% \text { no utilizaba condón en todas las ocasiones que tenía rela- } \\
\text { ciones sexuales, por lo que era vulnerable a enfermedades de transmisión } \\
\text { sexual. } \\
\text { Estos resultados coinciden con los informados en la literatura respecto al } \\
\text { comportamiento sexual de los adolescentes, en la que se ha documentado } \\
\text { que las relaciones sexuales de riesgo no se deben exclusivamente a la falta } \\
\text { de información. La investigación evidencia el papel del contexto familiar } \\
\text { como promotor o protector de conductas sexuales desfavorables en los ado- } \\
\text { lescentes. Se encuentra que estas conductas de riesgo estuvieron relacio- } \\
\text { nadas con la estructura, la comunicación y la expresión del afecto en la } \\
\text { familia. Entre las características familiares protectoras se señalan cercanía } \\
\text { afectiva, apoyo y aceptación, pues pueden bloquear la influencia negativa de } \\
\text { los pares, también se encuentra que la comunicación abierta y cálida con los } \\
\text { padres sobre la sexualidad propicia el uso responsable del condón. Entre los } \\
\text { factores de riesgo está la excesiva sobreprotección, imposición de muchas } \\
\text { reglas y no permitir que el joven decida. Por otro lado, los niveles bajos de } \\
\text { supervisión aceleran la independencia y contribuyen a que los adolescentes } \\
\text { asuman actitudes de adultos y se involucren en conductas inapropiadas. }\end{array}$ \\
\hline
\end{tabular}

Este estudio determina el estado de salud (nutricional, cognitivo, salud mental y educacional) y las conductas de riesgo para salud (delincuencia, abuso de sustancia, consumo riesgoso) de adolescentes expuestos toda su vida a plomo, y se incluyen a 40 adolescentes entre las edades de 12 a 19 años que habían participado en el programa de vigilancia infantil de exposición a plo-

México

Factors related to health outcomes

Cossio-Torres, Calderón, Téllez-Rojo, y Díaz-Barriga. (2013) and health risk behaviors of adolescents with lead exposure. A pilot study mo en un área metalúrgica de México. Los factores protectores identificados fueron volumen corpuscular medio, educación del adolescente, educación del padre y vivir en departamento. Los factores de riesgo fueron falta de horas de sueño, familia monoparental, familia con antecedentes de uso/abuso de sustancias, número de residentes en la vivienda, no tener seguridad social, plomo en tibia y plomo en sangre durante la infancia $(p<0.05)$. La detección de factores de riesgo y protección permitirá el diseño de un programa de intervención. La salud de los adolescentes puede mejorar aminorando factores de riesgo y fomentando factores de protección, desde lo individual, familiar o comunitario. 
Tabla 1.

Síntesis meta-analítica de los estudios sobre familia monoparental a nivel internacional.

\begin{tabular}{|c|c|c|}
\hline Autores (Año) & $\begin{array}{c}\text { Título del } \\
\text { estudio }\end{array}$ & Síntesis analítica \\
\hline $\begin{array}{l}\text { España } \\
\text { Rodríguez, } \\
\text { Del Barrio, y } \\
\text { Carrasco } \\
(2013)\end{array}$ & $\begin{array}{l}\text { Agresión física } \\
\text { y verbal en } \\
\text { hijos de familias } \\
\text { monoparentales } \\
\text { y biparentales: } \\
\text { el efecto } \\
\text { moderador del } \\
\text { sexo de los hijos }\end{array}$ & $\begin{array}{l}\text { Los resultados de esta investigación evidenciaron de manera consistente con } \\
\text { otros estudios que la agresión de los hijos era significativamente más elevada } \\
\text { en los chicos que en las chicas y en las familias monoparentales con madres } \\
\text { divorciadas que en las biparentales. Además, los varones que pertenecían a } \\
\text { una familia monoparental eran quienes mostraban mayores niveles de agre- } \\
\text { sión tanto física como verbal. En especial, las diferencias en agresión entre } \\
\text { los hijos de familias monoparentales de madres divorciadas y biparentales } \\
\text { emergían entre los varones pero desaparecian entre las mujeres. Los datos } \\
\text { hallados sugieren que ser hijo varón es un factor de riesgo para el desa- } \\
\text { rrollo de conductas agresivas, especialmente, cuando el niño se encuentra } \\
\text { dentro de una estructura familiar monoparental liderada por la madre. De } \\
\text { esto se desprende la necesidad de acciones preventivas para las familias } \\
\text { monoparentales constituidas por madres divorciadas con hijos varones. Las } \\
\text { limitaciones encontradas proponen investigar el uso de diferentes fuentes } \\
\text { para evaluar la agresión del niño. Estudiar si la agresión es consecuencia del } \\
\text { divorcio o de la nueva organización familia monoparental. }\end{array}$ \\
\hline
\end{tabular}

Este estudio basó sus conclusiones en el análisis teórico del concepto de familia monoparental, en el cual se le da especial relevancia al contexto sociocultural donde está inmersa. Aporta la posibilidad de aproximarse a

Hacia una tipología de

Cuba la familia Madrigal (2012) monoparental de tipo femenino. El caso cubano estudiar y abordar esta familia, desde la connotación positiva, pues la familia monoparental se le asocia con situaciones problemáticas, en detrimento de la figura femenina y de los hijos que viven a su cargo; sin embargo, no todos los casos representan riesgo social, ni necesitan la asistencia social o gubernamental. Le otorga importancia a los medios masivos de comunicación, al plantear la posibilidad de incluir programas de apoyo receptivos a la problemática de padres e hijos con la finalidad de aportar recursos educativos e instructivos a las familias monoparentales, para apoyar la atención a los hijos menores y promover educación sobre paternidad y maternidad responsable.

Los estudios sobre estrés materno durante la crianza infantil han considera-

Intervenciones psicológicas

Chile perinatales en depresión materna

Olaberry y Farkas (2012) y vínculo madre bebé: una revisión sistemática do variables contextuales para explicarlo. El nivel socioeconómico (NSE) así como la configuración familiar han sido variables relevantes, asociándose monoparentalidad en familias de bajos ingresos a mayores niveles de estrés materno. Se estudian los niveles de estrés materno en familias chilenas nucleares y monoparentales de NSE bajo, considerando el estrés en distintas dimensiones, asociado al rol materno, a la interacción madre-hijo y a la percepción de dificultades en el niño percibidas por la madre. Los resultados muestran niveles de estrés significativamente más altos en las madres pertenecientes a familias monoparentales asociado al rol materno, a la percepción del niño como difícil y en el estrés total.

Los estudios realizados en Francia evidencian que hay cambios en el tipo de familia tradicional y cada vez un menor número de adultos se casan y vienen aumentando las separaciones y relaciones de cohecho. Un factor interesante a estudiar es la disminución de la fecundación en menores de 25 años en la última década. A excepción de las cohortes nacidas antes de 1940 se ven menos afectados por el aumento en el divorcio, cuyas consecuencias todavía están en gran medida compensadas por el descenso de la mortalidad, lo que retrasa su viudez. 
Tabla 1.

Síntesis meta-analítica de los estudios sobre familia monoparental a nivel internacional.

\begin{tabular}{|c|c|c|}
\hline Autores (Año) & $\begin{array}{c}\text { Título del } \\
\text { estudio }\end{array}$ & Síntesis analítica \\
\hline $\begin{array}{l}\text { México } \\
\text { Ramos y } \\
\text { Maqueo (2010) }\end{array}$ & $\begin{array}{l}\text { Construcción de } \\
\text { un modelo de } \\
\text { riesgo } \\
\text { en el consumo de } \\
\text { alcohol y otras } \\
\text { sustancias ilícitas } \\
\text { en adolescentes } \\
\text { estudiantes de } \\
\text { bachillerato }\end{array}$ & $\begin{array}{l}\text { Este estudio es el resultado del tamizaje en un par de escuelas de bachillera- } \\
\text { to en Ciudad de México, con una muestra aleatoria simple estratificada (por } \\
\text { grado, turno y grupo) de la población total de dos planteles de bachillerato. } \\
\text { Se evaluaron } 52 \text { grupos, de un total de } 2.069 \text { alumnos, de estos solo se con- } \\
\text { sideraron datos válidos } 1.997 \text { por responder los cuestionarios de forma con- } \\
\text { sistente y por ser menores de } 21 \text { años de edad. Los datos muestran que los } \\
\text { chicos en riesgo viven en situaciones económicas, familiares y escolares difí- } \\
\text { ciles. Los datos arrojados son consistentes como los encontrados en estudios } \\
\text { anteriores, donde se ha identificado como factores de riesgo: pertenecer a } \\
\text { una familia monoparental (Farrel y White, 1998); tener bajos ingresos econó- } \\
\text { micos (Caballero, Madrigal, Hidalgo y Villaseñor, 1999); baja escolaridad de } \\
\text { los padres (Ramírez y Andrade, 2005); los padres pasen mucho tiempo fuera } \\
\text { de casa por motivos laborales (Jonson, La Voie y Mahoney, 2001). Otro factor } \\
\text { de riesgo es el bajo aprovechamiento escolar (promedio) y el turno, porque } \\
\text { los que asisten a la escuela por las tardes son estudiantes de mayor edad, } \\
\text { quienes tienen menor puntaje de calificaciones y presentan mayor probabili- } \\
\text { dad de consumo. La influencia del turno escolar ha sido poco documentado, } \\
\text { Nuño, Álvarez, Madrigal y Rasmussen (2005). }\end{array}$ \\
\hline
\end{tabular}

La investigación determina el perfil de la mujer que ha sufrido malos tratos, a partir de un estudio con 297 mujeres que reciben ayudas sociales por parte del Ayuntamiento de Valencia. La incidencia del maltrato en este grupo es

España Violencia de Género: perfil Gonzáles y de mujeres con Gimeno ayuda social (2009) del $37,3 \%$. El perfil de estas mujeres, en comparación con las mujeres del mismo grupo que no han recibido malos tratos, se caracteriza por ser de etnia paya, estructura familiar monoparental, estado civil separada, con varias relaciones de pareja previas y con problemas de salud psicológica. En otras variables que caracterizan a las mujeres receptoras de estas ayudas, tales como nivel de estudios, situación laboral, apoyos familiares y extra-familiares, no existen diferencias significativas. A partir de estos datos se plantean orientaciones para la prevención e intervención comunitaria.

Este trabajo resignifica la familia monoparental y evidencia que tienen una dinámica y estructura que las caracteriza. Por ello hoy, no se consideran como familias incompletas, ni vacías porque no se puede concebir que estas situaciones familiares son el resultado de la carencia y del fracaso. Es la ausencia de la figura paterna dentro del hogar un indicador de los problemas comportamentales de los adolescentes y de su vinculación con la madre, porque su falta de presencia física y emocional genera un funcionamiento diferente en cuanto a la posición de jerarquías que cada uno representa en el sistema familiar, y consecuentemente conlleva a la asunción de roles equívocos que alteran la comunicación. Por esta razón, se evidencian dos aspectos importantes a resaltar con relación a la jerarquía, por un lado, la relación paralela madre e hijo(a) y por otro lado, una relación en un nivel superior otorgado al hijo(a) con respecto a los hermanos, si los hay. 
Tabla 1.

Síntesis meta-analítica de los estudios sobre familia monoparental a nivel internacional.

\begin{tabular}{|c|c|c|}
\hline Autores (Año) & $\begin{array}{c}\text { Título del } \\
\text { estudio }\end{array}$ & Síntesis analítica \\
\hline $\begin{array}{l}\text { Le Gall } \\
\text { (2008) }\end{array}$ & $\begin{array}{l}\text { La evolución de la } \\
\text { familia en Francia. } \\
\text { De la aparición del } \\
\text { pluralismo familiar } \\
\text { a la cuestión de la } \\
\text { pluriparentalidad }\end{array}$ & $\begin{array}{l}\text { Describe a partir de indicadores sociodemográficos la evolución de la familia } \\
\text { en Francia a partir del año cincuenta, hasta hoy día. Se evidencia de un mo- } \\
\text { delo único de vida en familia a un pluralismo familiar. Además se destacan } \\
\text { fortalezas y debilidades de la familia contemporánea y abre la pregunta si las } \\
\text { nuevas formas de familia en que uno de los adultos no son los progenitores } \\
\text { (familias recompuestas, familias adoptivas, familias monoparentales y homo- } \\
\text { parentales), se unen al debate en varios países de Europa si un niño puede } \\
\text { tener varios padres y madres. Aquí se hace referencia al antropólogo Godelier: } \\
\text { "una nueva forma de parentesco está construyéndose en Occidente, donde la } \\
\text { familia no coincide necesariamente con la pareja" (2004). Se hace referencia } \\
\text { al principio universal: los padres no son siempre los progenitores, pero pueden } \\
\text { ser los que los alimentan, los educan o les garantizan el acceso a la adultez. } \\
\text { Sin embargo, se siguen generando dudas por la imposición del sistema de } \\
\text { filiación francés que dificulta la aclaración de los lugares y contribuciones de } \\
\text { cada uno. En este sentido, en Francia aparece una predisposición a no aceptar } \\
\text { este tipo de parentescos paralelos y en algunos casos se empieza a denotar } \\
\text { apertura frente a este tema. }\end{array}$ \\
\hline
\end{tabular}

\begin{tabular}{|c|c|c|}
\hline $\begin{array}{l}\text { Tinajero, } \\
\text { Camacho y } \\
\text { Gonzáles } \\
\text { ( 2007) }\end{array}$ & $\begin{array}{l}\text { Depresión } \\
\text { adolescente y } \\
\text { familia }\end{array}$ & $\begin{array}{l}\text { Este estudio considera que la depresión en adolescentes es multifactorial y } \\
\text { las mujeres adolescentes son más propensas a sufrir mayor depresión que } \\
\text { los hombres. También influye la estructura familiar, ya que la familia de tipo } \\
\text { monoparental aparece como factor de riesgo así como la reconstruida cuando } \\
\text { no existe comunicación. }\end{array}$ \\
\hline $\begin{array}{l}\text { México } \\
\text { Rodríguez } \\
(2004)\end{array}$ & $\begin{array}{l}\text { Estructura } \\
\text { familiar en } \\
\text { familias mexicano- } \\
\text { americanas. }\end{array}$ & $\begin{array}{l}\text { Resalta la importancia del progenitor que vive con los hijos, asuma su papel } \\
\text { no solo de jefe de la familia sino comprenda su papel formativo, se apoye en } \\
\text { redes sociales y fomente vínculos afectivos, comunicación clara para el buen } \\
\text { desarrollo de los hijos. }\end{array}$ \\
\hline
\end{tabular}

Las familias monoparentales tienen una estructura distinta de la familia nuclear, pero ese hecho en sí mismo, no nos permite deducir, desde un punto de monoparentales estructura tomada aisladamente o como única variable, no nos puede propor-

España en España: ¿una cionar la información suficiente para conocer la realidad social de las distintas desviación u formas de organización familiar y etiquetarlas sin antes profundizar en otros Arroyo. $\quad$ otra forma de (2002) organización social? factores que pueden ser tan importantes como la clase social, la educación, la socialización, etc. Por ello, se propone indagar cuáles son las variables, así como establecer qué se considera óptimo para el bienestar psicológico, físico y social de niños. Entonces, también se anima a los investigadores a considerar hasta qué punto la estructura es determinante en la dinámica familiar.

Las ciencias sociales han considerado a las familias monoparentales como una desviación de la familia nuclear y por ello, como un modelo negativo para la sociedad y los individuos, al tiempo que han destacado su incapacidad para cuidar a los niños de una manera normalizada. Muchos de los problemas aso-

\section{España}

Arroyo y Domínguez (2001).
Socialización de los hijos en familias monoparentales ciados a estas familias en la educación de los hijos parecen ser generados por situaciones de desventaja económica y riesgo de pobreza, y no tanto por la estructura familiar per se. Hay otros factores como la comunicación y la afectividad, que son fundamentales para el desarrollo de los niños. La monoparentalidad va a dar lugar a nuevas estrategias laborales, ya que la ausencia del cónyuge parece justificar la presencia de la mujer en el mercado de trabajo, aunque en circunstancias y condiciones muy diferentes, según sea la causa que ha originado dicha situación y el nivel de estudios del cabeza de familia. 
Tabla 1.

Síntesis meta-analítica de los estudios sobre familia monoparental a nivel internacional.

\begin{tabular}{|c|c|c|}
\hline Autores (Año) & $\begin{array}{c}\text { Título del } \\
\text { estudio }\end{array}$ & Síntesis analítica \\
\hline $\begin{array}{l}\text { Israel } \\
\text { Katz } \\
(2000)\end{array}$ & $\begin{array}{l}\text { Attitudes of } \\
\text { new immigrant } \\
\text { and veteran- } \\
\text { resident israeli } \\
\text { divorced mothers } \\
\text { toward single } \\
\text { motherhood }\end{array}$ & $\begin{array}{l}\text { Este estudio compara las actitudes de las madres divorciadas inmigrantes } \\
\text { con las de las residentes desde hace tiempo en Israel como jefes de familias } \\
\text { monoparentales. La comparación se centra en dos perspectivas: la actitud } \\
\text { personal y la actitud de la sociedad. Las encuestadas fueron } 100 \text { mujeres } \\
\text { divorciadas que emigraron desde la antigua Unión Soviética después de 1989, } \\
\text { y } 100 \text { mujeres divorciadas residentes desde hace tiempo en Israel. Las ma- } \\
\text { dres divorciadas inmigrantes, se divorcian por desacuerdo en la decisión de } \\
\text { emigrar y por el proceso de transculturización realizan ajustes para asimilar } \\
\text { la nueva cultura, así como el nuevo estilo de vida de hogar monoparental. } \\
\text { Adicionalmente, viven un ajuste entre su cultura de origen que considera el } \\
\text { divorcio como algo común y la cultura israelí que valora la familia como lo } \\
\text { central y estable de esta cultura. En consecuencia en este estudio se deter- } \\
\text { mina que la inmigración afecta la actitud personal, y de acuerdo a la percep- } \\
\text { ción social se considera por encima de los atributos demográficos. }\end{array}$ \\
\hline $\begin{array}{l}\text { Chile } \\
\text { Reinoso y } \\
\text { Serrat (1992) }\end{array}$ & $\begin{array}{l}\text { Familias } \\
\text { uniparentales } \\
\text { derivadas de } \\
\text { separación } \\
\text { matrimonial }\end{array}$ & $\begin{array}{l}\text { Se realiza un análisis del concepto de familia uniparental por causas de se- } \\
\text { paración, en el que se describe el proceso de reorganización familiar en } \\
\text { las diversas áreas del ciclo vital individual y familiar, se hace un llamado a } \\
\text { aumentar el número de investigaciones, así como a no generalizar, pues cada } \\
\text { familia según sus propios recursos personales y de apoyo social, responde de } \\
\text { manera diversa al proceso de reorganización familiar. }\end{array}$ \\
\hline
\end{tabular}

Sintetizando, la indagación realizada a nivel internacional se encuentran investigaciones de los años 2014 a 1992 en Buenos Aires, China, Cuba, Chile, México, España, Francia e Israel en el tema de familia monoparental que coinciden en su discusión que este tipo de familia tienen una dinámica diferente a la familia nuclear, se convoca a realizar diversos estudios sistemáticos, entre otros de variables correlacionales para explicar la forma como influye la estructura familiar monoparental en problemáticas de salud de los hijos, porque los resultados encontrados algunos lo determinan como factores de riesgo y otro no, cuando lo comparan con otras tipologías familiares.

En otras investigaciones los resultados relacionan familia monoparental con bajo rendimiento académico, depresión en adolescentes mujeres, ini- cio en adicciones en adolescentes hombres y en embarazos a edad temprana, perfil de mujeres que han recibido malos tratos por su pareja. Y se convoca a investigar sobre nuevos tipos de familia homoparental, monoparental, recompuesta, adoptiva y dar respuesta a la pregunta problémica: si un niño puede tener varios padres y madres a la vez. Además, se invita a los investigadores a estudiar otras variables como la estructura, el rol formativo del padre que queda a cargo de los hijos, el funcionamiento de la jerarquía, los vínculos afectivos, la educación, los recursos económicos, la socialización y el apoyo social. A continuación se relacionarán investigaciones realizadas en el contexto colombiano en los años 2011-2005 sobre la familia monoparental y aspectos estudiados en cuanto a variables o categorías. 
Tabla 2.

Síntesis Meta-analítica de los Estudios Sobre Familia Monoparental en Colombia.

\begin{tabular}{|c|c|c|}
\hline Autores (Año) & Título del estudio & Síntesis analítica \\
\hline $\begin{array}{l}\text { Gonzáles, } \\
\text { Carvajal y } \\
\text { Salcedo (2011) }\end{array}$ & $\begin{array}{l}\text { Consumo de SPA } \\
\text { en adolescentes } \\
\text { judicializados } \\
\text { bajo el sistema de } \\
\text { responsabilidad } \\
\text { penal entre 2009- } \\
2010\end{array}$ & $\begin{array}{l}\text { La investigación arrojó que la dinámica familiar es una variable importante } \\
\text { para el consumo de SPA, de la muestra estudiada ( } 66 \text { adolescentes) el } 21 \\
\% \text { pertenece a una familia extensa; el } 15 \% \text { a una familia monoparental. } \\
\text { Este estudio menciona que en Barranquilla sobre la dinámica familiar de } \\
\text { menores infractores se encontró un } 85,70 \% \text { perteneciente a familia mono- } \\
\text { parental, corresponde a la madre o al padre la responsabilidad de brindar } \\
\text { a los hijos la seguridad afectiva, la protección y la educación; sin embargo, } \\
\text { la ausencia de uno de ellos hace que el otro tenga que llevar el sustento } \\
\text { económico para satisfacer las necesidades básicas de la familia, dejando } \\
\text { de lado la supervisión de los hijos. Así pues, se encuentra que este tipo } \\
\text { de familia puede llevar al adolescente a adoptar conductas delictivas y de } \\
\text { consumo por la ausencia de la figura de autoridad. }\end{array}$ \\
\hline
\end{tabular}
consumo por la ausencia de la figura de autoridad.

Esta investigación cuantitativa describe características de la comunicación en familias de barrios subnormales de Montería. Se seleccionó una muestra intencional de 300 familias pertenecientes a cuatro asentamientos subnormales. Se aplicó dos encuestas, una midió características demográficas de La comunicación los hogares, y el cuestionario CFA creado por Garcés (2004) niveles de cofamiliar en

Garcés y

Palacio (2010) asentamientos subnormales de Montería municación familiar. Entre los hallazgos se resalta que las familias nucleares de estos barrios subnormales seleccionados mostraron mejor comunicación y relaciones que las monoparentales y extensas. Otro hallazgo significativo independientemente del tipo de familia es la figura materna quien desarrolla mejor comunicación afectiva y reguladora con los hijos. Otro aspecto encontrado son cuatro obstáculos para la comunicación familiar: separación de los padres, maltrato psicológico y físico, crisis económica y consumo de drogas.

Evidencia la necesidad de estudiar el conflicto en parejas en riesgo de separación y las formas de intervenirlo. Propone a los profesionales el reto de abordar y promover salud mental partiendo del conocimiento del con-

Análisis del proceso de comunicación en un proceso de mediación de conflictos con

Restrepo y Campos (2010) una pareja de separados, basado en la teoría de la acción comunicativa de Habermas y el modelo relacional simbólico flicto, si no se les dificulta accionar y situarse en lo que puede unir, relacionar, fortalecer vínculos y el capital social. El conflicto envuelve la relación de pareja y determina la forma en que se desarrolla el vínculo entre sus miembros, porque este es tanto afectivo como ético. Si no comprende esto el profesional, puede darse la separación que ocasiona una ruptura del vínculo afectando la relación de la pareja y con los hijos. Esto afecta la identidad, la forma de entender los intercambios afectivos, la posición en la familia y el rol en la sociedad. (Cigoli, 1999; Doltó, 1998a y Cigoli y Scabini, 2007). El estudio de caso de una pareja en proceso de separación plantea como interrogante: ¿cómo la mediación de conflictos es una herramienta que puede aportar al entendimiento de estas condiciones, en la medida que indague alternativas de intervención psicosocial que contribuyan constructivamente a desenvolver el conflicto subyacente en las parejas en procesos de separación, fundamentado en la aplicación de la pragmática formal del lenguaje y la racionalidad de la acción comunicativa desarrollada por Habermas? 
Tabla 2.

Síntesis Meta-analítica de los Estudios Sobre Familia Monoparental en Colombia.

\begin{tabular}{|c|c|c|}
\hline Autores (Año) & Título del estudio & Síntesis analítica \\
\hline $\begin{array}{l}\text { Buitrago-Peña, } \\
\text { Cabrera- } \\
\text { Cifuentes, y } \\
\text { Guevara-Jiménez } \\
\text { (2010) }\end{array}$ & $\begin{array}{l}\text { Las } \\
\text { representaciones } \\
\text { sociales de género } \\
\text { y castigo y su } \\
\text { incidencia en la } \\
\text { corrección de los } \\
\text { hijos }\end{array}$ & $\begin{array}{l}\text { Esta investigación cualitativa triangula información de la muestra selec- } \\
\text { cionada: familia nuclear, monoparental femenina o masculina. Se concluye } \\
\text { que el proceso de construcción de las Representaciones Sociales está dado } \\
\text { por las formas de crianza (creencias, pautas, prácticas, estilos) influyendo } \\
\text { significativamente en la diferenciación de correctivos empleados con los } \\
\text { hijos en las familias nucleares, pero no se evidencia en las familias mono- } \\
\text { parentales sean masculinas o femeninas. } \\
\text { Al identificar las diferencias entre la formación y crianza dada a los niños y } \\
\text { las niñas, se denota una mayor movilización y transformación respecto a las } \\
\text { representaciones sociales de castigo y género en las familias monoparenta- } \\
\text { les femeninas, evidenciando una ruptura del tradicional modelo patriarcal } \\
\text { de la crianza y posibilitando así el desarrollo de las niñas y los niños desde } \\
\text { el desarrollo de sus competencias y no desde el rol esperado para hombres } \\
\text { y mujeres. }\end{array}$ \\
\hline
\end{tabular}

Familias monoparentales con jefatura Uribe (2007) femenina, una de las expresiones de las familias contemporáneas
Se estudian los factores demográficos, culturales y económicos que han influido en este tipo de familia soportados en el marco de la Constitución Política en su artículo 43 que explicita la protección del Estado Colombiano a la mujer cabeza de familia, por esto se crea la Ley 82 de 1993, donde se expiden normas para apoyarla de manera especial y plantea la necesidad de crear estrategias de acción e intervención más acordes con las necesidades y desarrollos de las familias contemporáneas.

\section{Características} socioeconómicas, percepciones y dinámicas

Cepeda, Lesmes y Gutiérrez (2006)

familiares de un grupo de diez familias monoparentales con jefatura masculina ubicada en la ciudad de Bogotá

Descripción de la dinámica interna de las familias monoparentales, simultáneas, extendidas y Agudelo (2005) compuestas del municipio de Medellín, vinculadas al proyecto de prevención temprana de la agresión en niños
Proponen que se profundice más sobre la familia monoparental y sus tipología en el estilo de jefatura, porque como lo muestra la investigación es una realidad en constante crecimiento pero poco explorada por quienes tienen a su cargo la jefatura de la familia, porque se dan cambios en su rol al asumir ser padre y madre al mismo tiempo, en algunos casos tienen dificultades para orientar y fortalecer el desarrollo de sus hijos de acuerdo a sus demandas.

Estudia 536 familias de diferentes tipologías; extensa, monoparental con jefatura femenina o masculina y simultáneas; se les aplica un programa de Prevención Temprana de la Agresión, atendiendo a la totalidad de la población infantil y a las familias de las instituciones educativas seleccionadas, dado que para todas las tipologías, se reportan alteraciones en los procesos de su dinámica interna que marcan la necesidad de dar una atención preventiva y promocional para evitar la aparición y persistencia de comportamientos agresivos. Propone la creación de programas de educación familiar para que este tipo de familias pueda potencializar condiciones, relaciones y recursos para el crecimiento y desarrollo de sus miembros. No reporta el estudio que los niños de las diferentes tipologías estén expuestos a esquemas de autoridad, comunicación y afectividad que se consideran desfavorables para su desarrollo como autoritarismo, comunicación dañada y rechazo. 
Los estudios realizados en Bogotá, Medellín, Montería y Calarcá (Quindío) evidencian la necesidad de realizar investigaciones que relacionen variables específicas de la dinámica familiar monoparental: jerarquía, manejo de la autoridad, afectividad para relacionar o no la aparición en los hijos de dificultades socialmente relevantes porque los resultados no determinan que la salud mental de los hijos es determinante de la tipología de familia monoparental. Además se convoca a los investigadores a estudiar con rigurosidad otras aristas del fenómeno para soportar programas de intervención que fortalezcan su funcionamiento para el desarrollo, convivencia y bienestar de sus integrantes. Se señala que hoy se cuenta con mayor información sobre factores socioeconómicos, demográficos y esto ha generado por parte del Estado colombiano medidas de protección a madres cabezas de familia, tal como lo establece la Constitución Política como una forma de apoyar estas familias.

Para finalizar, una de las investigaciones recomienda la formación de recurso humano especializado con un enfoque teórico, epistemológico y metodológico para intervenir en los conflictos de la familia, en especial la monoparental mediante la mediación como lo plantea Rondón (2011).

\section{Discusión}

Resulta significativo que las investigaciones a nivel internacional y nacional, resaltan la importancia de los procesos sociales y la construcción de redes de apoyo social para la familia monoparental. Además, llama la atención a la sociedad para que de un nuevo lugar a este tipo de familia considerándola con una dinámica particular que la caracteriza pero que no es sinónimo de "familia incompleta".

Por ello, se enfatiza en el estilo de relación del padre o madre, en el papel formativo, independiente de cuál sea su conformación. Por último, se resalta la necesidad de investigadores de familias, para que diseñen y optimicen programas que contribuyan a la búsqueda de alternativas para una adecuada convivencia en este tipo de familia que va en aumento en el país, tal como lo plantea el estudio del Observatorio para la Equidad y la Integración Social en Medellín y Antioquia (2006).

Un aspecto relevante de los estudios de Cobos, Domínguez, y Arroyo (2008); Gómez, (2008); Luengo y Rodríguez (2003), es que las realidades familiares se complejizan en la medida en que se pueden observar en sus diversos contextos y del ciclo vital por el que está transitando. Esto marca el interés para investigar en familias monoparentales con jefatura femenina con hijos adolescentes y conocer sistemáticamente su dinámica: límites, reglas y comunicación, desde la psicología y desde el enfoque estructural de funcionamiento familiar.

Por ello, cobra fuerza investigar para precisar no solo los elementos planteados sino para comprender cómo los límites, las reglas y la comunicación definen la estructura y la organización de la familia monoparental, contribuyendo o no al desarrollo psicológico de todos sus miembros, en especial los adolescentes que están a su cargo, cómo dirigen la familia, cómo acompañan al hijo adolescente en la construcción de su identidad, en su proceso de socialización, cómo previenen problemas socialmente relevantes: adicciones, embarazos a edades tempranas, delincuencia juvenil, violencia de género, etc. Desde esta perspectiva se resaltan los aportes de Añon y Miravet (2005); Sala y Collado (2009); Viveros, Arias y Castro (2006); Meil (2010); Alcalde-Campos y Pávez (2013), frente al valor que tiene el conocimiento de la idiosincrasia en la formulación de políticas públicas que permitan promover el desarrollo de los adolescentes con calidad de vida, de cara a las problemáticas de mayor prevalencia en el análisis del funcionamiento familiar.

Se concluye que en los procesos psicológicos básicos para una familia monoparental con jefatura femenina, es fundamental trabajar el ejercicio de la jerarquía, el posicionamiento de la madre como autoridad, establecimiento de normas y reglas claras, el empoderamiento y la reflexión acerca de su propia historia de vida. Por esto, se toman los estudios de Chapelli, (2010); Gonzáles, (2010); Grupo de Investigación Alter (2008), que afirman que el trabajo con la madre de manera individual 
permite la aceptación de estructuras en cuanto a su visión de la figura masculina, que a su vez genera expectativas fantasiosas hacia su hijo, permitiendo este abordaje cambios que fortalezcan el vínculo madre e hijo.

A partir de esta perspectiva meta-analítica, se han identificado diferentes tópicos que resaltan la necesidad y pertinencia de avanzar en el desarrollo de estudios comprensivos sobre la realidad compleja y el análisis sistémico de la dinámica, funcionamiento y estilos de vida emergentes en familias monoparentales, en coherencia con aportes de Rozo (2003) el paradigma del pensamiento complejo.

Para finalizar, Vanegas, Barbosa, Alfonso, Delgado y Gutiérrez (2012); Bikel (1982); Carranza (1982); Loreto Tamara y Valenzuela (2012), señalan que los investigadores de familia tienen la responsabilidad de realizar estudios sistemáticos sobre características, estructura y organización familiar que permita construir teorías, metodologías en el contexto colombiano para el diseño de programas de intervención, en pro de reconstruir vínculos para redes de apoyo del padre o madre con su familia de origen o la de su expareja, para educar y formar a los hijos, buscar recursos en el contexto social para ejercer su nuevo rol parental y los hijos puedan comprender su rol dentro de esta nueva estructura y tipo de familia. La finalidad es que quien ejerce la paternidad en este tipo de familia pueda contribuir en la construcción de la identidad del hijo(a) y enseñarlo(a) a desenvolverse en situaciones vulnerables.

\section{Referencias}

Alter Grupo de Investigación. (2008). Monoparentalidad y Exclusión Social. Recuperado de

http://www.unavarra.es/digitalAssets/168/168 636_10000005-Monoparentalidad-y-exclsuion -social-PDF.pdf

Agudelo, B. M. (2005). Descripción de la dinámica interna de las familias monoparentales, simultáneas, extendidas y compuestas del municipio de Medellín, vinculadas al proyecto de prevención temprana de la agresión. Latinoamericana de Ciencias Sociales, Niñez y Juventud, 3(1), 1-19.

Alcalde-Campos, R., y Pávez, I. (2013). Infancia, familias monoparentales e inmigración latinoamericana en Barcelona, España. Latinoamericana de Ciencias Sociales, niñez y juventud, 11(1), 229-243.

Andolfi, M. (1984). Terapia Familiar. Buenos Aires: Paidós.

Anqi, X., y Yan, X. (2014). The changes in mainland chinese families during the social transition: a critical analysis. Journal of comparative family studies, 45(1), 31-53.

Añón, M. J., y Miravet, P. (2005). Paradojas del familiarismo en el estado del bienestar: mujeres y renta básica. Cuadernos de Relaciones Laborales, 23(2), 101-121.

Arroyo, A., y Domínguez, M. (2001). Socialización de los hijos en familias monoparentales. Revista de Educación, 325, 99-112.

Arroyo, M. (2002). Las familias monoparentales en España: ¿Una desviación u otra forma de organización social? Tesis doctoral no publicada. Madrid, España: UCM.

Barker, G., y Verani, F. (2008). La participación del hombre como padre en la región de Latinoamérica y el Caribe: una revisión de literatura crítica con consideraciones para políticas. Recuperado de http://www.lazoblanco.org/ wp-content/uploads/2013/08manual/bibliog/ material paternidades_0090.pdf

Bertalanffy, L. (1992). Teoría de Sistemas. México: Fondo de Cultura Económica.

Bikel, R. (1982). Las etapas de la vida familiar: transición y cambio. Terapia familiar: estructura, patología y terapeútica del grupo familiar, 5(9), 59-71.

Bouche, J., y Hidalgo, F. (2003). IV Curso de Experto Universitario en Mediación y Orientación Familiar 2003-2004. Madrid: Dykinson S. L. 
Buitrago-Peña, M., Cabrera-Cifuentes, K., y Guevara-Jiménez, M. (2010). Las representaciones sociales de género y castigo y su incidencia en la corrección de los hijos. Educación y Educadores, 12(3), 53-71.

Carrasco, E. (1998). Terapia Familiar y Psiquiatría Infantil. Revista de Familias y Terapias, 5(9), 31-38.

Cepeda, J., Lesmes, M., y Gutiérrez, J. (2007). Cuáles son las características socioeconómicas, percepciones y dinámicas familiares de un grupo de diez familias monoparentales con jefatura masculina ubicada en la ciudad de Bogotá. Recuperado de http://repository.lasalle. edu.co/bitstream/10185/13432/1/62022062. pdf

Cervini, R., Dari, N., y Quiroz, S. (2014). Estructura familiar y rendimiento académico en países de América Latina: los datos del segundo estudio regional Comparativo y Explicativo. Revista Mexicana de investigación educativa, 19(61), 569-597.

Chapelli, A. (2010). Paternidad y Monoparentalidad: acercamiento a su estudio. Revista Contribuciones a las Ciencias Sociales. 3(1), 1-2.

Cobos, E., Domínguez, M., y Arroyo, A. (2008). Adolescencia y familia: revisión de la relación y la comunicación como factores de riesgo o protección. Revista intercontinental de psicología y educación, 10(2), 105-122.

Cossio-Torres, P., Calderón, J., Téllez-Rojo, M., y Díaz-Barriga, F. (2013). Factors related to health outcomes and health risk behaviors of adolescents with lead exposure. A pilot study. Salud Mental, 36(1), 73-81.

Cusinato, M. (1992). Psicología de las relaciones familiares. Barcelona: Herder.

Garcés, M., y Palacio, S. (2010). La comunicación familiar en asentamientos subnormales de Montería (Colombia). Psicología desde El Caribe, 26, 1-29.

García, R., y Constante, E. (2011). Revisiones: las claves para el estudio de la familia mono- parental en el contexto psicosocial. Revista Fundesfam, 6(1), 51-62.

Gómez, C. E. (2008). Adolescencia y familia: revisión de la relación y la comunicación como factores de riesgo o protección. Revista intercontinental de psicología y educación, 10(2), 105-122.

Gonzáles, O. J. (2010). Las familias monoparentales en la comunidad autónoma de la región de Murcia. Recuperado de http//www.carm. es/web/integra.servlets.Control_Publico?ID CONTENIDO $=886 \& I D I T I P O=140 \&$ rastro $=c 819$ $\$ \mathrm{~m} /$ publicaciones

González, Y., Carvajal, A., y Salcedo, M. (2011). Consumo de SPA en adolescentes judicializados bajo el sistema de responsabilidad penal entre 2009-2010 en Calarcá. Revista electrónica Poesis, 22. Recuperado de http://www. funlam.edu.co/revistas/index.php/poiesis/ issue/view/12

Hernández, Á. (2005). Familia, ciclo vital y psicoterapia sistémica breve. Bogotá: El Búho.

Jociles, M., Rivas, A., y Moncó, B. (2008). Una reflexión crítica sobre la monoparentalidad: el caso de las madres solteras por elección. Portularia, 8(1), 265-274.

Katz, R. (2000). Attitudes of New Immigrant and Veteran- Resident Israeli Divorced Mothers Toward Single Motherhood. International Migration, 38(5), 83-97.

Iglesias de Ussel, J. (1988a). Las familias monoparentales. En J. Iglesias (ed.). La situación de la familia en España y los nuevos modelos familiares monoparentales, 23-40 Madrid, España: Ministerio de Asuntos Sociales.

Lavielle-Sotomayor, P., Jiménez-Valdez, F., Vázquez-Rodríguez, A., Aguirre-García, M., Castillo-Trejo, M., y Vega-Mendoza, S. (2014). Impacto de la familia en las conductas sexuales de riesgo de los adolescentes. Revista médica del IMSS, 52(1), 38-43.

Lefaucher, N. (1988). Las familias monoparentales. En J. Iglesias de Ussel (ed.). Existen las 
familias monoparentales, 155-162. Madrid, España: Ministerio de Asuntos Sociales. Instituto de la Mujer.

Le Gall, D. (2008). La evolución de la familia en Francia. De la aparición del pluralismo familiar a la cuestión de la pluriparentalidad. Espacio Abierto. Cuaderno venezolano de sociología, 17(4), 631-655.

López, A., y Parada, A. (1999). Psicología de la comunicación, 139-151. Bogotá: Alfa-Omega.

Loreto, M., Tamara, G. y Valenzuela, M. (2012). Evaluación del programa "Familias fuertes: amor y límites" en familias con adolescentes de 10 a 14 años. Revista Médica Chile, 140(6), 726-731.

Luengo, T., y Rodríguez, C. (2003). Un análisis del concepto de familia monoparental a partir de una investigación sobre núcleos familiares monoparentales. Revista de sociología, 69, 59-82.

Madrigal, D. (2012). Hacia una tipología de la familia monoparental de tipo femenino. El caso cubano. En contribuciones a las ciencias sociales. Recuperado de http://www.eumed. net/rev/cccss/17/dyml.html

Meil, L. G. (2010). Responsabilidad parental y monoparentalidad: análisis socio jurídico. Recuperado de http://www.fes-web.org/uploads/ files/modules/congress/10/grupos-trabajo/ ponencias/296.pdf

Minuchin, S. (1984). Calidoscopio familiar. Madrid: Paidós.

Minuchin, S. (2003). Familias y terapia familiar. Barcelona: Gedisa.

Montañés, M., Bartolomé, R., y Montañés, J. (2008). Influencia del contexto familiar en las conductas adolescentes. Ensayos, 23, 391-407.

Observatorio para la Equidad y la Integración Social en Medellín y Antioquia. (2006). Viaje al interior de la familia: análisis sobre cambios y tendencias, tipología y conflictos, procesos de acompañamiento social. Recuperado de http://www.bapp-eafit/uploads/docs/OBO26 0219.pdf

Olhaberry, M., y Farkas, Ch. (2012). Estrés materno y configuración familiar: estudio comparativo en familias chilenas monoparentales y nucleares de bajos ingresos. Universitas Psychologica, 11(4), 1.317-1.326.

Oviedo, N. (1982). Mejoramiento de las reglas de comunicación en la familia. Terapia familiar, 5(9), 119-136.

Peck, S., y Manocherian. (1988). Divorce in the changing family life cycle. Changing family life cycle, 15, 335-369.

Prioux, F., Mazuy, M., y Barbieri, M. (2010). Recent Demographic Developments in France: Fewer Adults Live with a Partner. Population, 65(3), 363-413.

Ramos, M., y Maqueo, E. (2010). Construcción de un modelo de riesgo en el consumo de alcohol y otras sustancias ilícitas en adolescentes estudiantes de bachillerato. Health \& Addictions / Salud \& Drogas, 10(1), 79-96.

Reinoso, A., y Serrat, C. (1992). Familias Uniparentales derivadas de separación matrimonial. Psykhe, 1(1), 101-111.

Restrepo, M., y Campos, O. (2010). Análisis del proceso de comunicación en un proceso de mediación de conflictos con una pareja de separados, basado en la teoría de la acción comunicativa de Habermas y el modelo relacional simbólico. Diversitas: Perspectivas Psicológicas, 6(1), 123-134.

Ritvo, E., y Glick, I. (2003). Terapia de pareja y familia. México: Manual Moderno.

Rodrigáñez, C. (2008). Poner límites o informar de los límites el amor después de la etapa primal. Cuándo se cambian las órdenes por la información y la complacencia. Recuperado de http://www.lagatzara.files.wordpress. com/.../c-rodrigac3b1ezponer 
Rodríguez, J. (2011). Estructura familiar en familias mexicano-americanas. Revista de la Fundación para el estudio de la atención de la familia, 50(1), 77-91.

Rodríguez, P. (2004). La familia en Iberoamérica. Convenio Andrés Bello. Colombia: Nomos S.A.

Rodríguez, M. A., Del Barrio, M., y Carrasco, Y. A. (2013). Agresión física y verbal en hijos de familias monoparentales divorciadas y biparentales: el efecto moderador del sexo de los hijos. Revista de psicopatología y psicología clínica, 18(2), 119-127.

Roizblatt, A. (2006). Terapia familiar y de pareja. Santiago: Mediterráneo.

Rondón, L. (2011). Nuevas formas de familia y perspectivas para la mediación: el tránsito de la familia modelo a los distintos modelos familiares. Recuperado de space.unia.es/bitstream/ handle/10334/1691/4Rondon.pdf?sequence=3

Rozo, J. (2003). Sistémica y pensamiento complejo. I paradigmas, sistemas, complejidad. Antioquia: Biogénesis.

Sala, F., y Collado, A. (2009). Violencia de género: perfil de mujeres con ayuda social. Psychosocial Intervention/Intervención Psicosocial, 18(2), 165-175.

Sánchez-Gutiérrez, D. (2000). Terapia familiar. Modelos y técnicas. México: Manual Moderno.

Schlesinger, B. (1969). The One Parent Family. Perspectives and Annotated Bibliography, Toronto: University of Toronto Press.
Thomas, F. (14 de agosto de 2013). La familia en crisis: ¿Cuál familia en crisis? El Tiempo. Recuperado de http://www.eltiempo.com/archivo/documento/CMS-12990648

Tinajero, M., Camacho, S., y Gonzáles, M. (2007). Depresión adolescente y familia. Boletín AMUP, 10(47), 17-26.

Uribe, P. (2012). Aprender a ser familia. Familias monoparentales con jefatura femenina: significados, realidades y dinámicas. Revista tendencias \& retos, 17(2), 131-133.

Uribe, P. (2007). Familias monoparentales con jefatura femenina, una de las expresiones de las familias contemporáneas. Revista Tendencias \& Retos, 12(1), 81-90.

Valdivia, C. (2008). La familia concepto, cambios y nuevos modelos. Revista la Revue du REDIF, 1(1), 15-22.

Vanegas, G., Barbosa, A., Alfonso, M., Delgado, L. y Gutiérrez, J. (2012). Familias Monoparentales con hijos adolescentes y psicoterapia sistémica: una experiencia de intervención e investigación. Revista vanguardia psicológica, 2(2), 203-215.

Viveros, E., y Arias, L. (2006). Dinámicas internas de las familias con jefatura femenina y menores de edad en conflicto con la Ley Penal: características interaccionales. Medellín: Departamento de Publicaciones Fundación Universitaria Luis Amigó.

Watzlawick, P., Beavin J., y Jackson, D. (1985). Teoría de la comunicación humana. Barcelona: Herder. 